\title{
A Method for Measuring the Density of Fine - Grained Solids
}

\author{
Li Ning \\ Yunnan Phosphate Chemical Group Co., Ltd., Kunming, China
}

Email address:

Lin962@126.com

\section{To cite this article:}

Li Ning. A Method for Measuring the Density of Fine - Grained Solids. Modern Chemistry. Vol. 7, No. 2, 2019, pp. 27-29. doi: $10.11648 / \mathrm{j} . \mathrm{mc} .20190702 .11$

Received: August 7, 2019; Accepted: August 29, 2019; Published: September 17, 2019

\begin{abstract}
Density is an inherent property of matter, which plays a very important role in production and life. There are many and relatively simple methods to measure the density of large particulate matter. But the density measurement of fine-grained solid materials is difficult because of the volume measurement. Existing methods require expensive and complex equipment. In order to measure the density of fine solids in a simple, convenient, accurate and rapid manner, This paper uses water to fill the gap between the particles of materials, and then through the conversion of water mass and volume, so as to calculate the volume of materials, so as to calculate the density of fine-grained materials. This paper takes fine-grained phosphate ore as an example to demonstrate the application method of this study. The density of phosphate ore measured by this method is $2.84 \mathrm{~g} / \mathrm{cm}^{3} \mathrm{cubed}$, which is consistent with the theory. Steel ball and copper chip are also used for verification, and the calculated density is close to the theoretical density, which verifies the accuracy and reliability of this method. Through research and demonstration, this method can make it easy, fast and accurate to measure the density of fine solids, save time and investment, and improve efficiency and efficiency.
\end{abstract}

Keywords: Measurement, Fine Grained Solids, Density

\section{Introduction}

Density is one of the characteristics of the material, its meaning is the quality of the material per unit volume. Because of this, the density in the life has many applications, such as according to the different substance density difference between identification, density identification of material is a kind of nondestructive testing methods, has advantages of high accuracy, high speed, simple method [1-2], calculation is very difficult to weigh the quality of the object or the volume of a complex object shape, solid - liquid two phase flow density and concentration of mutual conversion, etc. In a word, the density of matter plays an important role in production and life, so it is particularly important to measure the density of matter.

Bulky solid density measurement is relatively simple, has high precision, measurement methods have scales measuring cylinder method, buoyancy method, such as, the lever balance method, etc. [3], JiaoLi scale, constant hydrostatic said method, the hydrostatic balance and pycnometer method, hydrometer or meter method, westphal weight balance, combined with the Archimedes' principle and lever or spring dynamometer can directly read out the solid density, etc. [4-11]. All of its methods are basically to measure the mass of the substance and so on, then measure the volume of the substance (and based on the large volume of the substance, which is easy to measure), and finally calculate the density using the ratio of mass to volume.

For the density measurement of fine solids, it is a little more complicated than that of large pieces. For example, the density measurement method of cement has automatic true density analyzer, but the equipment investment is large and the operation is complicated [12-13]. One-step method to measure the density of substances, which is filled with flour and other solids, and has a large error due to the gaps between flour particles and between flour particles and the measured objects [14]. Because of the current density measurement of fine solids, the equipment investment is large, the operation is complicated, or the measurement is not accurate. Therefore, a simple and accurate measurement method of flotation phosphate ore is studied in this paper.

\section{Basic Calculation of Density}

Density means the mass of the unit volume of the substance, 
which is calculated as the ratio of mass to volume of the substance, that is,

$$
\rho=M / V
$$

In, $\rho$ - The density of matter, $\mathrm{g} / \mathrm{cm}^{3}$;

$M-$ The quality of the substance, $\mathrm{g}$;

$V$ - Volume of matter, $\mathrm{cm}^{3}$.

The above calculation formula needs to measure the quality and volume of the substance before the density of the substance can be calculated. However, in real production and life, the volume of many fine-grained solids is difficult to measure directly, resulting in density measurement difficulties.

\section{A Study of a New Method of Density Measurement}

In view of the difficulty of the difficulty of the volume of fine-grained solids, this method can simply measure the volume of fine-grained solids and calculate the density.

\subsection{Test Preparation}

Capacity bottle (volume according to particle size selection, the need for particles can be poured into it, in this article using $\mathrm{V}_{\mathrm{b}}=250 \mathrm{ml}$ ), electronic balance (precision $0.1 \mathrm{~g}$ ), glass rod, solid particles (using $-0.074 \mathrm{~mm}$ particle size content greater than $75 \%$ of phosphorus ore).

\subsection{The Trial Process}

Weighing a certain amount of phosphorus ore powder $M S$ (The trial is $200.0 \mathrm{~g}$ without water), The quality of the bottle is claimed $M_{b}(100.1 \mathrm{~g})$, Then pour the mineral powder into the capacity bottle, in the capacity bottle first add about $200 \mathrm{~g}$ of water, cover the cork, the mineral powder and water shake well, to drain the air between the powder, reduce the error. Then add water to the tick marks., The total mass of the bottle, mineral powder and water at this time is said to be $M_{b+s+w}$ $(478.9 \mathrm{~g})$, The quality of the water at this time is $M w=M_{b+s+w}-M_{s}-M_{b}$, And according to the relationship between water density and temperature [15], that is

$$
\rho w=-0.000003 \mathrm{Tw} 2-0.000108 \mathrm{Tw}+1.000937
$$

In: $\rho_{w} \longrightarrow$ Water density, $\mathrm{g} / \mathrm{cm}^{3}$;

$T_{w} \longrightarrow$ The temperature of the water, ${ }^{\circ} \mathrm{C}$.

Measure the temperature at the time and calculate the density of the water by formula to calculate the volume of the water at this time $V w=M w / \rho w$, Thus, the volume of the powder can be calculated $V s=V b-V w$. At this point, the quality and volume of the powder have been measured, the density of the powder can be calculated using the formula.

$$
\rho=\mathrm{M} / \mathrm{V}=\mathrm{Ms} /(\mathrm{Vb}-(\mathrm{Mb}+\mathrm{s}+\mathrm{w}-\mathrm{Ms}-\mathrm{Mb}) / \rho \mathrm{w})
$$

In, $M_{s} \_$The quality of the substance to be tested, $\mathrm{g}$;

$V_{b}-$ Capacity bottle volume, $\mathrm{cm}^{3}$;

$M_{b+s+w}$ Total mass of capacity bottles, substances to be tested, water, g;

$M_{b} \quad$ Capacity bottle quality, g;

$\rho_{w}-$ The density of the water at the test temperature, $\mathrm{g} / \mathrm{cm}^{3}$.

In general industrial production, the density of water can be approximated $1 \mathrm{~g} / \mathrm{cm}^{3}$ in the production of low precision requirements, the volume of the substance to be measured is not affected by temperature, if the application of higher accuracy requirements should consider the effect of temperature on water density and material volume.

\subsection{Test Results}

From the above preparation and testing process, $\mathrm{V}_{\mathrm{b}}=250 \mathrm{ml}$, $\mathrm{M}_{\mathrm{b}}=100.1 \mathrm{~g}, \mathrm{M}_{\mathrm{s}}=200.0 \mathrm{~g}, \mathrm{M}_{\mathrm{b}+\mathrm{s}+\mathrm{w}}=478.9 \mathrm{~g}$, The test temperature is $30^{\circ} \mathrm{C}$, The density of water at the time of the test is $0.9955 \mathrm{~g} / \mathrm{cm}^{3}$, From this it can be calculated $\mathrm{V}_{\mathrm{w}}=179.58 \mathrm{~cm}^{3}$, Volume of mineral powder $\mathrm{V}_{\mathrm{s}}=70.42 \mathrm{~cm}^{3}$, According to the formula (3) The density of the mineral powder can be calculated as $2.839 \mathrm{~g} / \mathrm{cm}^{3}$.

Phosphorus ore density is about $2.85 \mathrm{~g} / \mathrm{cm}^{3}$, The measurement is similar to the density of phosphorus ore, and the difference may be due to the nature of the ore itself, internal pores, or parcels with other substances, conjoined and measurement errors.

\subsection{Accuracy Verification of Methods}

In order to verify the accuracy of this research method, the steel beads and copper chips are used respectively to verify the

\begin{tabular}{|c|c|c|c|c|c|c|c|c|}
\hline Name of substance & $\begin{array}{l}\text { Material } \\
\text { weight/g }\end{array}$ & $\begin{array}{l}\text { Bottle } \\
\text { weight/g }\end{array}$ & $\begin{array}{l}\text { Water } \\
\text { weight/g }\end{array}$ & $\begin{array}{l}\text { Total } \\
\text { weight/g }\end{array}$ & $\begin{array}{l}\text { Water } \\
\text { volumec/m³ }\end{array}$ & $\begin{array}{l}\text { Material } \\
\text { volume } / \mathrm{cm}^{3}\end{array}$ & $\begin{array}{l}\text { Measuring } \\
\text { density } \mathrm{g} / \mathrm{cm}^{3}\end{array}$ & $\begin{array}{l}\text { Theoretical } \\
\text { density } \mathbf{g} / \mathrm{cm}^{3}\end{array}$ \\
\hline \multirow{3}{*}{ Steel Ball } & 399.7 & 100.1 & 197.6 & 697.4 & 198.49 & 51.51 & 7.76 & \multirow{3}{*}{7.85} \\
\hline & 273.4 & 100.1 & 214.1 & 587.6 & 215.08 & 34.92 & 7.83 & \\
\hline & 185.1 & 100.1 & 225.4 & 510.6 & 226.45 & 23.55 & 7.86 & \\
\hline \multirow{3}{*}{ Copper chips } & 436.7 & 100.1 & 199.9 & 736.7 & 200.77 & 49.23 & 8.87 & \multirow{3}{*}{8.90} \\
\hline & 314.5 & 100.1 & 213.7 & 628.3 & 214.70 & 35.30 & 8.91 & \\
\hline & 201.9 & 100.1 & 226.2 & 528.2 & 227.26 & 22.74 & 8.88 & \\
\hline
\end{tabular}
results as shown in Table 1.

Table 1. Method Validation.

Note: The temperature at the test time was 30 degrees $\mathrm{C}$, depending on the formula (2), the density of water is $0.9955 \mathrm{~g} / \mathrm{cm} 3$.

From the verification data, the density measured by this method is very small difference from the theoretical density of the substance, which shows that it is accurate and reliable and can be used for the density measurement of low precision requirements in production and life. 


\section{Conclusion}

The method can simply and accurately measure the density of small solids that do not react with water, and it can also be measured by replacing water with other liquid media.

The accuracy of the measurement using this method is affected by the internal wrapping of other substances, sorcets and internal pores in the measuring material.

In general industrial production, the density of water can be approximated $1 \mathrm{~g} / \mathrm{cm}^{3}$ in production with low accuracy requirements, and the volume of the substance to be measured is not affected by temperature, which can simplify the calculation, and if the application of higher accuracy requirements, the effect of temperature on water density and material volume should be considered.

\section{References}

[1] She Shu-qun. "Study on determination of gold in decoration by x-ray fluorescence with density correction". Geological Exploration For Non-ferrous Metals, vol. 7, no. 3, pp. 182-185, 1998.

[2] Zhang Xun-biao. "Wonderful density gold method". Shanghai Metrology and Testing, no. 6, pp. 41-42, 1995.

[3] Zhang Ling. "Several common ways to measure density in mid-test questions". Mathematical Learning (Junior Edition), vol. 25, no. 9, pp. 48-50, 2018.

[4] Li Yin-lun. "Testing the Density of Substance with Jouly Steelyard". Journal of Qinghai Junior Teachers' College (Natural Science Edition), no. 3, pp. 43-44, 2000.

[5] He Sheng-jing. "Physical experiment manual". Beijing: Machinery Industry Press, 1989.
[6] Wang Yun-cai. "University physics experiment course". Beijing: Science Press. 2008.

[7] He Sheng-jing, Wang Xing-nai. "Physical experimental dictionary”. Beijing: Science and General Press, 1991.

[8] Huang Tian-ming. "Hydrostatic measurement of solid density by cubic weighing method". Physical Bulletin, no. 3, pp. 34-35, 1998.

[9] Li Yan-hong. "Inspection and use of density bottle". Beer Technology, no. 9, pp. 42-44, 2006.

[10] Qi Jian-jun, Xiao Hua. "Two special methods for measuring the density of matter". Physical Bulletin, no. 5, pp. 37-37, 2003.

[11] Wu Hao-rang. "Systematic error analysis and correction of density measurement of objects by static equilibrium method". Jurnal of zhang jia kou teachers college, vol. 19, no. 6, pp. 55-56, 2003.

[12] Yin Xiang-nan, Wang Chang-an, Wang Wei-zhi, etc. "Application of automatic true density analyzer in determination of cement density". Cement, 2019 (supplement): 145-147.

[13] Wang Yue. "Analysis of influencing factors of cement density inspection". China cement, no. 3, pp. 89-90, 2019.

[14] Zhang Hong-yun, Yang Yong-liang, Meng bo. "Design of one-step method for measuring material density". Physical Bulletin, no. 4, pp. 82-84, 2016.

[15] Ren Li, Li Guang-yong, Wang xun, etc. “Application of Water Density Correction Method to Converse Formation Pressure in Water Injection Well". Oil and gas well testing, vol. 21, no. 3, pp. 24-25, 2012. 